\title{
CAMINHOS PARA A LEITURA LITERÁRIA EM LÍNGUA FRANCESA NA EDUCAÇÃO INFANTIL
}

\author{
PATHS TO LITERARY READING IN FRENCH IN CHILDHOOD \\ EDUCATION
}

\author{
Josilene PINHEIRO-MARIZ*
}

\begin{abstract}
Resumo: Nestas reflexões, apontamos a literatura endereçada às crianças e aos jovens leitores, produzida em língua francesa e originária de países africanos, como um potencial caminho na aprendizagem de uma língua estrangeira, a exemplo do francês. Tal proposta está também ancorada na Lei Federal 10.639/03, que orienta quanto ao ensino da cultura africana e afro-brasileira, o que, sob o nosso prisma, é uma abertura especial para se formarem leitores mais tolerantes em relação ao outro. Expomos argumentos que dão suporte às discussões sobre o ensino de uma língua estrangeira na infância (GAONAC'H, 2006; VANTHIER, 2009) e também sobre a abordagem da literatura na escola (POSLANIEC, 2000; CHELEBOURG; MARCOIN, 2007; REYES, 2010), pelas trilhas da língua alvo, ressaltando-se o quanto é indispensável ler e aprender desde cedo. Legitimando essas discussões, apresentamos dados de pesquisa que recensearam obras literárias infantojuvenis de países africanos de língua francesa, colocando em destaque a produção feminina e a importância de se apresentarem aos jovens leitores vieses para uma visão não sexista (ADICHIE, 2017) a partir da leitura das obras literárias.
\end{abstract}

Palavras-chave: Ensino. Literatura. Língua francesa. Leitura. Infância.

\begin{abstract}
Literature addressed to children and young readers, written in French and from African countries can be seen as a potential path to learn French as a foreign language. The proposal is anchored in Brazilian legislation (Law 10.639 /03), which provides guidance for teaching African and AfroBrazilian culture and that can be seen as a special opening to form more empathic readers. This paper reviews discussions about foreign language teaching in childhood (GAONAC'H, 2006; VANTHIER, 2009), as well as the approaches to literature at school (POSLANIEC, 2000; CHELEBOURG; MARCOIN; 2007; REYES, 2010 to discuss research inventories of children literature from Frenchspeaking-African countries, highlighting women writings. Emphases is given to the importance of reading and learn from an early age and of introducing, to young readers, ways to non-sexist views (ADICHIE, 2017) from reading literary works.
\end{abstract}

Keywords: Teaching. Literature. Language. Reading. Childhood.

\section{Introdução}

No âmbito das práticas e metodologias, pensando-se na educação literária no ensino básico, voltamos o nosso olhar para o ensino infantil ${ }^{1}$, sem deixarmos de olhar também para o ensino de crianças acima dessa faixa-etária; trazemos para esta discussão, a educação literária

\footnotetext{
* Professora Associada da Universidade Federal de Campina Grande (UFCG). Doutorado em Letras pela Universidade de São Paulo (USP). E-mail: jsmariz22@ hotmail.com.

${ }^{1}$ Entendendo Ensino Infantil segundo o Ministério da Educação e Cultura (BRASIL, 2020): “A educação infantil é um direito humano e social de todas as crianças até seis anos de idade, sem distinção decorrente de origem geográfica, caracteres do fenótipo (cor da pele, traços de rosto e cabelo), da etnia, nacionalidade, sexo, de deficiência física ou mental, nível socioeconômico ou classe social”.
} 
centrada no âmbito do ensino e/ou aprendizagem de uma língua estrangeira, tendo em vista que é uma antiga inquietação nossa pensar o lugar da literatura quando se aprende uma língua estrangeira (AIALA; MELLO, 2015; ARRUDA, 2016, dentre outros)², além de ser também tema de discussões de diversos especialistas, a exemplo de Poslaniec (2000), Vanthier (2009) e Gaonac'h (2006). Dito de outra forma, um dos questionamentos que embasam estas reflexões dão conta da pergunta: por que quem estuda uma língua estrangeira (doravante LE) tem contato com textos literários apenas quando tem uma formação mais sólida da língua? Esta inquietação é constatada ao se consultar livros didáticos para o ensino da língua francesa ou mesmo em diálogos com colegas, professores de línguas estrangeiras. Ademais, Peytard (1982) já apontava a negligência quanto à presença dos textos literários nos livros didáticos para o ensino do francês, por exemplo. Sendo este, portanto, o ponto de partida para as discussões deste texto, dando-se foco à educação pela e com a literatura, contribuindo também para o ensino e aprendizagem de uma língua estrangeira.

Diante dessa conjuntura, pensar o ensino de línguas para crianças e pensar tal procedimento pelos caminhos da literatura não se constitui, exatamente, em uma discussão simples, tendo-se em conta que é indispensável trazer ao debate elementos teóricos e de pesquisas que devem ancorar estas ponderações. Por essa razão, para melhor expor as ideias que podem mostrar os Caminhos para a leitura literária em língua estrangeira no ensino infantil, faz-se necessário contextualizar alguns elementos que julgamos fundamentais para dar sustentação às discussões.

A ausência do ensino da língua francesa no currículo da escola básica não pode se constituir em um obstáculo para pensarmos nas mais diversas possibilidades de ensino dessa língua nos vários níveis escolares. Muito embora essa língua não esteja presente no ensino básico, projetos de ensino e de extensão têm sido realizados em diversas universidades brasileiras, o que revela que se trata de uma realidade exequível.

As razões que chancelam esta escolha têm uma relação direta com a atuação profissional do professor ou professora de uma língua que não seja a portuguesa ${ }^{3}$. Ao lado desse fato, acrescente-se que temos aqui dois eixos a serem acompanhados: um que vê a essencialidade da educação literária no ensino infantil e o outro que reconhece importância de aprender uma nova

\footnotetext{
${ }^{2}$ Conferir referências: Aiala e Mello (2015); Arruda (2016); Pinheiro-Mariz e Lira (2018; 2019); Pinheiro-Mariz e Florêncio (2017); Pinheiro-Mariz (2011) e outros.

${ }^{3}$ Neste artigo, utilizaremos o termo língua estrangeira como sinônimo de língua adicional ou outras diversas conceitualizações ligadas ao termo. Ressalte-se apenas que essa escolha tem relação direta com o fato de entendermos a aprendizagem de uma língua "outra" como um processo que passa pela alteridade, que articula e mobiliza diversos outros conhecimentos.
} 
língua desde a mais tenra idade. Ao reunir esses dois eixos, as nossas discussões tomam um fôlego que tem alimentado pesquisas de iniciação científica (2013-2020), que serão paulatinamente referendadas aqui, na proporção que formos desenvolvendo as discussões.

Portanto, pensar na educação literária pode ajudar a compreender o quanto é fundamental levar a literatura à criança desde cedo na sua formação humana complexa e integral, algo que vai para além da educação escolar, considerando-se que a escola pode contribuir na formação. Dessa forma, um meio de a escola ter métodos para ajudar em tal formação diz respeito à busca por caminhos como o da prática leitora no intento de expor a criança às diversas formas de estímulo à imaginação e a uma formação mais completa. É com esse olhar que especialistas, a exemplo de Reys (2010) e Poslaniec (2000), dentre muitos outros, têm dedicado estudos que fortalecem e esclarecem razões para expor a criança à leitura literária desde cedo. Dentre os argumentos, destaca-se que nos primeiros anos de vida, a criança tem uma maior capacidade de estímulo ao desenvolvimento cultural e social.

Ao pensarmos no outro eixo, concebemos que a aprendizagem de uma nova língua, cedo na infância, traduz-se em uma atividade que estimula novas descoberta na vida da criança, pois ao identificar novos sons, novos significados e novas culturas, a criança pode se tornar um adulto mais tolerante, sobretudo, ao reconhecer todo um mundo mais amplo à sua volta. Segundo pesquisadores como Vanthier (2009), é imprescindível reconhecer a importância de aprender uma nova língua desde cedo, pois essa aprendizagem pode ser um meio frutuoso para propiciar os prazeres da descoberta. O prazer de uma língua nova pode ser uma das primeiras descobertas da criança, o que pode levá-la a outras descobertas de novos horizontes. Por esse viés, com os pés nessas duas linhas, entendemos que ao trabalhar em prol da formação literária no ensino de uma língua estrangeira, podem-se reunir valores que darão uma formação mais sólida, que é vital à criança.

Para este artigo, trazemos primeiramente as nossas ponderações sobre a necessária formação literária no ensino de uma LE; e, na sequência, passamos às reflexões que embasam esse ensino na infância, abrindo caminhos para uma educação plurilíngue e pluricultural. Em seguida, trazemos discussões imprescindíveis como as que dão conta da leitura literária pelos caminhos da "francofonia"⿻4 no ensino da língua francesa. O que traremos à luz é a importância

\footnotetext{
${ }^{4}$ Optamos por utilizar o termo entre aspas, de modo reiterado, uma vez que entendemos que nele subjazem discussões que não se fazem necessárias neste texto. Utilizaremos o termo literatura de língua francesa como sinônimo dessa mesma noção ligada à "francofonia".
} 
de, em nosso país, propor-se leituras e discussões de literaturas africanas, uma vez que a Lei $10.639 / 03^{5}$ orienta sobre o ensino da cultura afro-brasileira.

Para apresentar as literaturas africanas de língua francesa endereçadas às crianças (atividade que pode também ser feita junto a adolescentes), traremos dados de pesquisas de iniciação científica que abrangem um período que vai de 2013 a 2020 e que descortinam uma clara possibilidade de se estimular o ensino de línguas, tendo a leitura literária como o foco principal para a abertura de novos horizontes, logo, para a formação literária. Os nossos principais resultados estão ancorados em levantamentos de obras dirigidas ao público infantil e juvenil em países africanos do Magrebe e Maxerreque e da África Subsaariana, todos de língua francesa. Esse inventário de obras tem, em princípio, o público infantil como alvo; no entanto, as obras literárias para jovens também nos interessam, pois, de maneira geral, as obras identificadas ressaltam a riqueza da literatura "dita francófona" e nos faz identificá-la como basilar para o ensino da língua francesa para crianças brasileiras, podendo estimular trocas interculturais e instigar à tolerância em relação ao diferente, o que é imprescindível na infância, ratificando-se que o fato de ser uma língua que não é comum no ensino infantil brasileiro configura-se como um ponto fulcral para ampliação de horizontes culturais, ao contrário do que propõe a Base Nacional Comum Curricular (BNCC, 2018), ao orientar sobre a necessidade de ampliação linguística e cultural a partir unicamente da língua inglesa. Nesse sentido, a abordagem da literatura em língua francesa, ao lado do ensino da língua inglesa poderia, de fato, promover ampliação de horizontes culturais.

Na catalogação feita, identificamos um número significativo de textos que, de alguma forma, são acessíveis ao leitor de língua francesa e destacamos alguns elementos que vislumbramos como importantes de serem observados, tais como o período das publicações (em um recorte de 1980 a 2015), realçando os gêneros literários mais produzidos e em quais países há uma maior produção e, enfatizamos que dentre as últimas publicações do período, a obra literária feminina endereçada ao público infantojuvenil é uma das mais florescentes. $\mathrm{O}$ que, na nossa perspectiva é um dado fundamental para se discutir desde cedo na formação humana, a fim de ajudarmos na formação de seres humanos mais tolerantes. Ao final, trazemos as considerações quase finais, pois, em se tratando de literatura no ensino de línguas para crianças, estamos sempre fazendo descobertas.

\footnotetext{
${ }^{5}$ Altera a Lei no 9.394, de 20 de dezembro de 1996, que estabelece as diretrizes e bases da educação nacional, para incluir no currículo oficial da Rede de Ensino a obrigatoriedade da temática "História e Cultura Afro-Brasileira", e dá outras providências.
} 


\section{A leitura literária sob uma perspectiva de abertura de horizontes linguísticos}

Iniciamos esta seção com questionamentos que parecem ter sido recorrente em meio aos profissionais de ensino de línguas: como e para quê ensinar uma língua estrangeira a uma criança, se ela ainda não tem domínio do próprio idioma? Se há vantagens em se ensinar uma língua estrangeira nesse período, quais são? Os especialistas tais como os que dão base a estas reflexões entendem que quanto antes se começa a alfabetizar a criança em outra língua, mais cedo essa criança poderá administrar essa aprendizagem e, até mesmo, melhorar a aquisição da própria língua. Isto porque o período da infância é o mais adequado para tal aprendizagem, podendo acontecer em paralelo à aquisição da língua materna da criança. Acrescente-se a isso que nessa fase da vida, o cérebro da criança ainda está em fase de desenvolvimento, podendo fazer a aquisição da nova língua com muito mais facilidade que em outras fases da vida, como a adolescência ou em idade adulta (GAONAC'H, 2006).

Partindo-se dessas afirmações, acrescentamos discussões, à luz de pesquisas e de argumentos, razões que sustentam o porquê de se ensinar uma língua outra na infância. Ao aprender uma língua estrangeira, a criança se depara com o outro como sujeito de linguagem, podendo ser este oriundo de diferentes lugares e, consequentemente, de diferentes culturas (VYGOTSKY, 1995), o que, por certo, pode contribuir para dar a ela uma significativa amplitude do seu mundo. Ora, sabe-se que o contato com outras línguas, logo, com culturas diversas, pode ser um elemento desencadeador para o desenvolvimento do comportamento da tolerância deste futuro adulto.

A especialista colombiana Yolanda Reyes, autora de um dos mais importantes projetos sobre leitura literária na infância da América Latina, o Espantapájaros, lembra que "a primeira infância se define como período do ciclo vital dos seres humanos que se estende desde a etapa intrauterina até os seis anos de idade" (REYES, 2010, p.18). Nessa afirmação, subjaz que crianças, nessa fase, estão mais suscetíveis às mais variadas formas de aprendizagens, dentre as quais está a de uma nova língua, levando-se em consideração que têm maiores possibilidades tanto no que diz respeito à maturação, quanto à aprendizagem.

Isto se dá porque a plasticidade do cérebro infantil é quase ilimitada (GAONA'CH, 2006; VANTHIER, 2009), comportamento que faz a criança estar mais hábil para aprender uma LE. Pode-se dizer ainda que essa realidade está diretamente ligada ao fato de que, na infância, a aprendizagem acontece de maneira mais intensa, pois nessa fase da vida a flexibilidade cerebral é evidente, conforme confirmas as neurociências. Estudos como o de Mora (2004) afirmam que a sinaptogênese têm mostrado que há uma relação entre a capacidade de formação de novas 
conexões, sinapses, entre as células cerebrais e as ligações neuronais, possibilitando a plasticidade cerebral pode modificar tanto a química, quanto a anatomia e a fisiologia cerebral alterando as redes neuronais diante de estímulos ambientais distintos, incitando o aparecimento de novas sinapses, quando liberados novos neurotransmissores. Portanto,

\footnotetext{
Oferecer situações de aprendizagem fundamentadas em experiências ricas em estímulos e fomentar atividades intelectuais pode promover a ativação de novas sinapses. As informações do meio, uma vez selecionadas, não são apenas armazenadas na memória, mas geram e integram um novo sistema funcional, caracterizando com isso a complexificação da aprendizagem (CARVALHO, 2010, p. $521)$.
}

É, consequentemente, indispensável que a criança seja colocada diante dos mais variados estímulos, a fim de provocar a liberação de novos neurotransmissores; e, sob a nossa ótica, o desafio de aprender outra língua logo cedo, a partir de leituras literárias, pode ser uma atividade que permitirá essa experiência rica em estímulos, pois instiga à aprendizagem de um novo código, o linguístico. Quando tal estímulo é oferecido ao lado da leitura literária, essa experiência pode ser potencializada, pois, em sendo uma atividade intelectual, evidentemente, irá estimular a ativação das novas sinapses. Acrescente-se que segundo Carvalho (2010) não se está afirmando que a criança irá tão somente colocar imagens linguísticas no cérebro /memória; segundo a pesquisadora, o resultado é mais amplo, pois o armazenamento das informações ajuda a gerar o conhecimento, considerando-se que tais informações integram o novo sistema funcional; daí, portanto, toda a complexidade da aprendizagem que deve ser entendida como um conjunto de processos neurobiológicos e neuropsicológicos ligados à memória.

Ora, é considerando toda essa complexidade que entendemos a importância do ensino da língua para crianças pelos caminhos da literatura. Na infância, o intricado processo de aprendizagem ocorre de modo inconsciente; daí dizer-se que, nesse período da vida, na realidade, ocorreria a aquisição de estruturas linguísticas e um dos elementos mais importantes para que esse processo ocorra está ligado ao imaginário infantil, uma espécie de mundo paralelo que está bastante presente em várias fases da vida do infante. Para Reyes (2010), nesse contexto, involuntariamente, a criança administra esse mundo imaginário partindo de sua própria realidade; e, por essa razão, é importante que a literatura seja ofertada a ela desde cedo, logo nos primeiros anos de vida, pois ela, a literatura, pode ser entendida como uma " [...] fonte de nutrição a que a criança recorre em busca de ferramentas mentais e simbólicas para organizar o fluxo dos acontecimentos e situar-se e revelar-se e decifrar-se, também ela, na cadeia temporal instaura na linguagem" (REYES, 2010, p. 63). Mesmo que ainda não leia, a literatura pode ser 
contada, nos primeiros anos de vida, pois é o estímulo ao imaginário que permitirá a liberação de novos neurotransmissores e o aparecimento de novas sinapses, segundo afirmam os diversos pesquisadores da área (POSLANIEC, 2002; GAONA'CH, 2006; VANTHIER, 2009; REYES, 2010). Cabe ressaltar que embora esteja se referenciando campos de saberes distintos, estes não são divergentes, sobretudo quando consideramos a complexidade do ser humano. Para além de se formar seres humanos mais inteligentes, reiteramos aqui a importância da humanização na aprendizagem, o que pode ser potencializado pela leitura literária desde cedo.

Hélène Vanthier (2009), especialista no ensino de línguas estrangeiras para crianças, entende que um dos caminhos mais impactantes para o ensino de uma língua estrangeira às crianças é a literatura, pois, ao ouvir as estórias ou ver as ilustrações dos livros, a incitação do imaginário é tão forte que pode se constituir em uma importante fonte de prazer para o pequeno leitor que entra em contato com descobertas que o levam a conhecer novos personagens, ambientes e contextos socioculturais diversos, promovendo, dessa maneira, o prazer de ouvir, inclusive, a nova língua. Por essa razão, do mesmo modo que se tem ciência da importância da leitura literária logo na primeira infância, é necessário colocar a criança diante do "novo" que podem ser os sons da língua-alvo, pois ela - a criança - "armazena" tais elementos com pouco esforço, em virtude de que, nessa fase, tudo pode ser entendido como brincadeira pra ela. É a própria especialista francesa quem ressalta que a literatura infantojuvenil pode se constituir em um espaço de encontros, pois ver-se diante do outro é fundamental para dar à criança um necessário suporte na construção de suas referências imaginarias que, certamente, se entrecruzarão com as referências ficcionais, dando-se, portanto, o suporte necessário para a construção da própria identidade infantil, visto que a criança é confrontada com o outro.

Sob o nosso prisma, Vanthier (2009) nos faz uma ponte indispensável para o argumento do ensino de língua estrangeira na infância pelos caminhos da literatura; porém, é outro especialista em leitura que dá o suporte para avançarmos pelas trilhas que nos propomos a caminhar, pois para o também autor de obras literárias, Christian Poslaniec, o encontro com o livro e até mesmo com o seu autor é uma forma única de proporcionar descobertas culturais que podem auxiliar na formação integral da criança. Poslaniec (2002) ainda afirma que, mesmo que a criança ainda não seja leitora do texto escrito, o livro - enquanto conjunto literário formado por diversos elementos, dentre os quais, a imagem - é um elemento fundamental para incitar a interação entre o mundo da criança e o novo, que é apresentado a ela, seja através da leitura ou mesmo da contação. A isso, acrescentamos que, ao associar os conhecimentos adquiridos ao longo da vida aos novos conhecimentos, a criança é estimulada à criação e à interpretação, pois, diante do novo, do desafio, ela é levada a passar por um processo de amadurecimento de 
diversos sistemas, como o fonatório, sem traumatismos, como acontece, às vezes, na fase adulta. Nesse contexto, a maturação não acontece apenas em um aspecto específico, pois tudo é muito interligado e a criança passa por tudo isso de maneira quase imperceptível para ela, embora seja bastante notada pelo adulto que a acompanha.

Logo, toda essa complexidade cria um ambiente assaz confortável para que a língua materna seja também um elemento a contribuir na aprendizagem da língua estrangeira. Desse fato, depreende-se que as descobertas associadas ao imaginário são fundamentais para consolidar a aprendizagem de uma nova língua; de modo muito especial, quando se tem na literatura a principal mediadora para esse fim. A respeito da literatura como mediadora, Candido (2004) apresenta uma fundamental discussão no seu Direito à literatura, e a partir dessa noção, pode-se ampliá-la, levando-a para o universo dos pequenos. Isso porque a obra literária é capaz de ajudar a criança no enfrentamento aos desafios sociais e culturais, que naturalmente se apresentam, como se fosse um jogo; além de dar, por assim dizer, um suporte emocional ao pequeno leitor, contribuindo ainda para um amadurecimento emocional, levandoo a identificar-se com personagens da ficção, podendo, até mesmo, conduzi-lo à catarse.

E quando esse texto literário, de alguma forma, articula de modo mais intenso a aproximação entre o universo imaginário da criança e o ficcional da literatura? Por esse caminho, então, seguimos nas nossas discussões; e, no nosso entender, ao se levar em consideração todas as variáveis implicadas nessa equação, identificamos na literatura de língua francesa produzida no continente africano uma das forças de maior propulsão para tal ensino. A dita literatura "francófona" pode ser, no nosso entender, uma das principais passagens para levar a criança, na nossa realidade brasileira, a vivenciar as experiências do outro e, sobretudo, a experienciar a descoberta de outros horizontes culturais e linguísticos.

\section{A literatura "dita francófona" africana para crianças e jovens}

Realçando a importância do ensino de uma língua estrangeira na primeira infância e da imprescindibilidade da leitura literária como mediadora, quando se tem a literatura de língua francesa do continente africano, é possível identificar de maneira mais concreta elementos que especialistas reforçam como características importantes à obra literária infantojuvenil, a exemplo de Chelebourg e Marcoin (2007). Para esses especialistas, a obra endereçada a crianças e também a jovens leitores seria fundada em três importantes pilares: edificação, educação e recreação. Tradicionalmente, sabe-se do cuidado do professor em não apenas pedagogizar a obra, nem tampouco fazer dela um elemento para educar ou punir o aprendiz, como parece ter acontecido historicamente. Tal realidade nos é trazida à memória por um dos principais 
pesquisadores da área, o historiador Philippe Ariès (2017), ao ressaltar que, em um período pós Século das Luzes, a literatura passou a ter esse papel pedagogizante. Entretanto, para além de ensinar, com elementos que contribuem para a edificação da criança, a literatura, com sua força estética, pode provocar evasão, dentre outras reações no leitor. Faz-se ainda necessário lembrar que, embora tenha sido, de certa forma, marginalizada ao longo de muitos anos, muito provavelmente por ser entendida como "simples", a literatura infantojuvenil, hoje, ocupa um espaço importante nos estudos literários em um âmbito universal e, exatamente por essa razão, enfocamos a que é produzida nos países de língua francesa do continente africano.

Pelos caminhos do empirismo, observamos na literatura de língua francesa africana um espaço que também consegue, e de modo muito especial, reunir esses elementos indispensáveis para a evasão necessária na formação da criança, contribuindo para a descoberta de outra língua e de outros mundos. Assim, pensando a leitura literária como recreação, é possível identificar obras em forma de quadrinhos, livros ilustrados, livros-jogos e em outros diversificados formatos. Ao final deste texto, apresentamos algumas dessas obras, a partir de uma seleção feita em sete anos de projetos de iniciação científica realizados no período entre 2013 a $2020^{6}$.

Inicialmente, apresentamos o levantamento feito por gêneros da literatura infanto-juvenil de língua francesa produzida na África e regiões insulares africanas; e, posteriormente, identificamos as obras por países. Cabe evidenciar que, na investigação das obras, buscamos selecionar aquelas que, segundo os especialistas, poderiam ser classificadas como obras literárias para crianças e jovens leitores, revelando temas apreciados pelo público-alvo, pois abordavam assuntos variados como aventuras heroicas, mistério e fantasia, presença de príncipes e princesas, família e amizade, além de questões sociais, lições de vida, dentre outros.

As pesquisas em nível de iniciação científica desenvolvidas no período anteriormente citados foram de base bibliográfica e documental e os principais meios de acesso às obras foram bibliotecas virtuais e também livrarias especializadas, tais como a Livraria Présence Africaine, Livraria Gibert Joseph, Livraria do Institut du Monde Arabe e a Livraria do Musée du Quai de Branly e Livraria Qobaa. Uma parte significativa desses livros foram adquiridos para a leitura e também para dar suporte aos nossos estudos. Nos dois gráficos abaixo, é possível verificar a variedade de gêneros publicados nos países de língua francesa do continente africano, destacando-se as grandes regiões nas quais estão essas publicações. No arrolamento das obras, grosso modo, (conf. Anexo), constatou-se que, na África subsaariana, no período entre $1980 \mathrm{e}$

\footnotetext{
${ }^{6}$ Em projetos de Iniciação Científica (PIBIC), Josilene Pinheiro-Mariz coordenou as pesquisas com as bolsistas estudantes de graduação Jéssica Rodrigues Florêncio (2013-2016), Manuella Barreto Bitencourt (2016-2018) e Ana Beatriz de Aquino Silva (2018-2020).
} 
2015, ocorreu a publicação de 73 obras com as características que destacamos acima, enquanto, ao norte do continente, foram detectadas 28 obras no Magrebe e 12 no Maxerreque, mais precisamente, no Egito. É possível depreender desses dados o fato de existirem mais de 30 países ao sul do Grande Deserto que têm o francês como língua oficial ou segunda, enquanto ao norte a quantidade de países é bem menor, nomeando-se: Marrocos, Argélia, Tunísia, Mauritânia e Líbia, na região magrebina, e o Egito, na região do Maxerreque, que ainda conta com outros países, a saber: Iraque, Palestina, Jordânia, Síria e Líbano, que estão no continente asiático. Muito provavelmente, essa é a razão que revela essa grande diferença entre as duas regiões ${ }^{7}$.

No gráfico 2, observa-se que nos países nos quais se pôde localizar publicações no período em estudo há uma discreta representatividade, enquanto em outros países da região parece ainda haver uma carência de obras com as características buscadas.

Gráfico 1 - obras por gênero

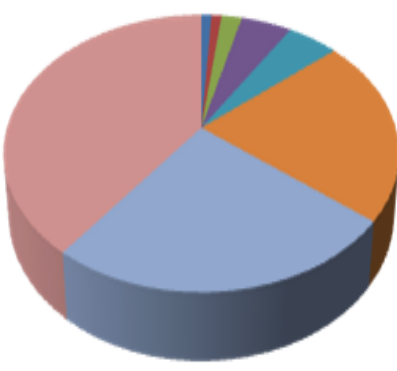

- Peça (teatro): 1

- Poesia: 1

- Livro de imagens: 2

- Documentários: 5

- Novelas: 5

- $\mathrm{HQ}: 22$

Inomances: 25

II Contos: 40

Fonte: Elaborado pelas pesquisadoras
Gráfico 2 - África Subsaariana
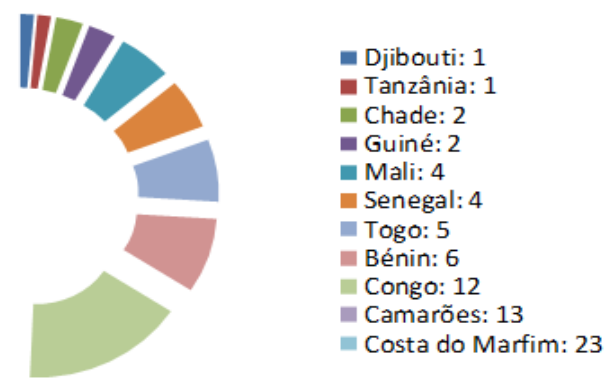

Fonte: Elaborado pelas pesquisadoras

Outro dado importante a se destacar é a diversidade de gêneros enquanto uma realidade nas literaturas das regiões africanas e, nesse âmbito, destaca-se o gênero conto, o que pode ser deveras simbólico, uma vez que o referido gênero é uma das marcas da literatura daquele continente, conforme se pode observar no gráfico acima. Ao lado desse expressivo dado concernente ao conto, destaca-se a ausência de poemas, o que pode ratificar o comentário a respeito do conto enquanto tradição e evidentemente, em especial, o de tradição oral, marca africana.

\footnotetext{
${ }^{7}$ É importante dizer ainda que temos uma pesquisa em andamento que cataloga a produção infantojuvenil da região que nomeamos Áfricas insulares, isto é, países independentes e Departamentos Ultramarinos franceses localizados no Oceano Índico. Os resultados preliminares revelam que, assim como em outras regiões do continente, há uma significativa produção literária voltada para esse público.
} 
Ainda se verifica, a partir dos dados do gráfico 2, que há países, a exemplo da Costa do Marfim e do Camarões, em que a produção é bastante relevante, no que se subentende um número mais convincente de casas editoriais, estimulando, por consequência, a produção de escritores daqueles países. Nesse sentido, é importante expor um dado que pode reiterar o que estamos discutindo. Trata-se de um vivaz aumento de publicações com esse foco nos últimos 10 anos, conforme revela o gráfico 3, na sequência:

Gráfico 3 - obras publicadas em 30 anos

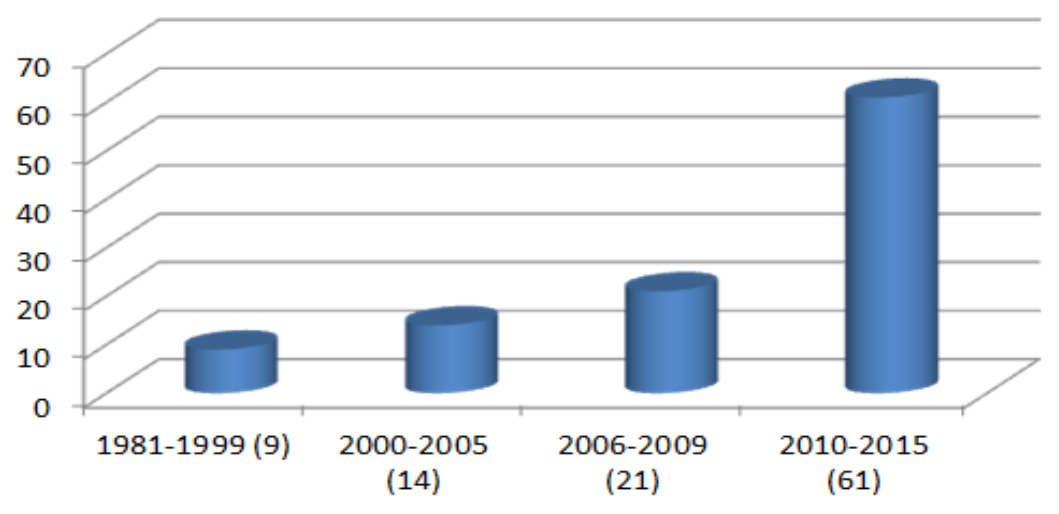

FONTE: Elaborado pelas pesquisadoras

As publicações recentes podem significar que, com a popularização da internet, as obras passaram a ser mais acessíveis, uma vez que podem ser vendidas em formato eletrônico também, ou pode ser que, de fato, haja mais escritores preocupados em propor leituras literárias para as crianças dos países que revelaram uma produção mais acentuada. Em recente estudo, Miranda e Florêncio (2019) destacam a produção literária para crianças na África, ressaltando a importância do conto no contexto da tradição oral.

Nos últimos anos, portanto, no que diz respeito à produção literária para crianças, há um cuidadoso trabalho de valorização de elementos culturais africanos, conforme se pode observar no gráfico acima; e as temáticas têm abraçado não somente temas tradicionais da infância, como os já anteriormente citados, mas também temáticas ligadas à autonomia e à pós-colonialidade. “Com isso, observa-se que a literatura africana é um retrato e a voz de um povo que há algum tempo vem ganhando espaço e, nesse sentido, a literatura vem sendo um dos principais instrumentos para a sua difusão" (MIRANDA; FLORÊNCIO, 2019, p. 201).

Diante desses dados e na continuidade da pesquisa, naturalmente, chegamos à autoria dessas obras, o que nos chamou a atenção, pois mesmo diante de toda a tradição patriarcal muito comum naquele continente, identificamos que o número de autoras era bastante significativo. Mesmo sendo ainda uma minoria, há um número considerável de mulheres escrevendo para 
crianças e jovens, com temas que abordam desde o lugar da mulher na sociedade, até doenças como a Síndrome da Imunodeficiência Adquirida, tão comum em muitos países africanos. Os nossos dados trazem à luz que das 105 obras repertoriadas, 56 são de autores e 43 de autoras, que também participam de 6 obras em conjunto com algum autor.

O próximo gráfico desvela que o aumento da produção de literatura infantojuvenil em países de língua francesa do continente africano tem um forte protagonismo feminino. O que pode ainda ratificar o comentário anterior que concerne ao fato de serem jovens países independentes, estando ainda em face de uma construção nacional identitária, logo, podem ser países em que a mulher tem ocupado espaços importantes na sociedade.

Gráfico 4 - produção de autoras de 1980 a 2015

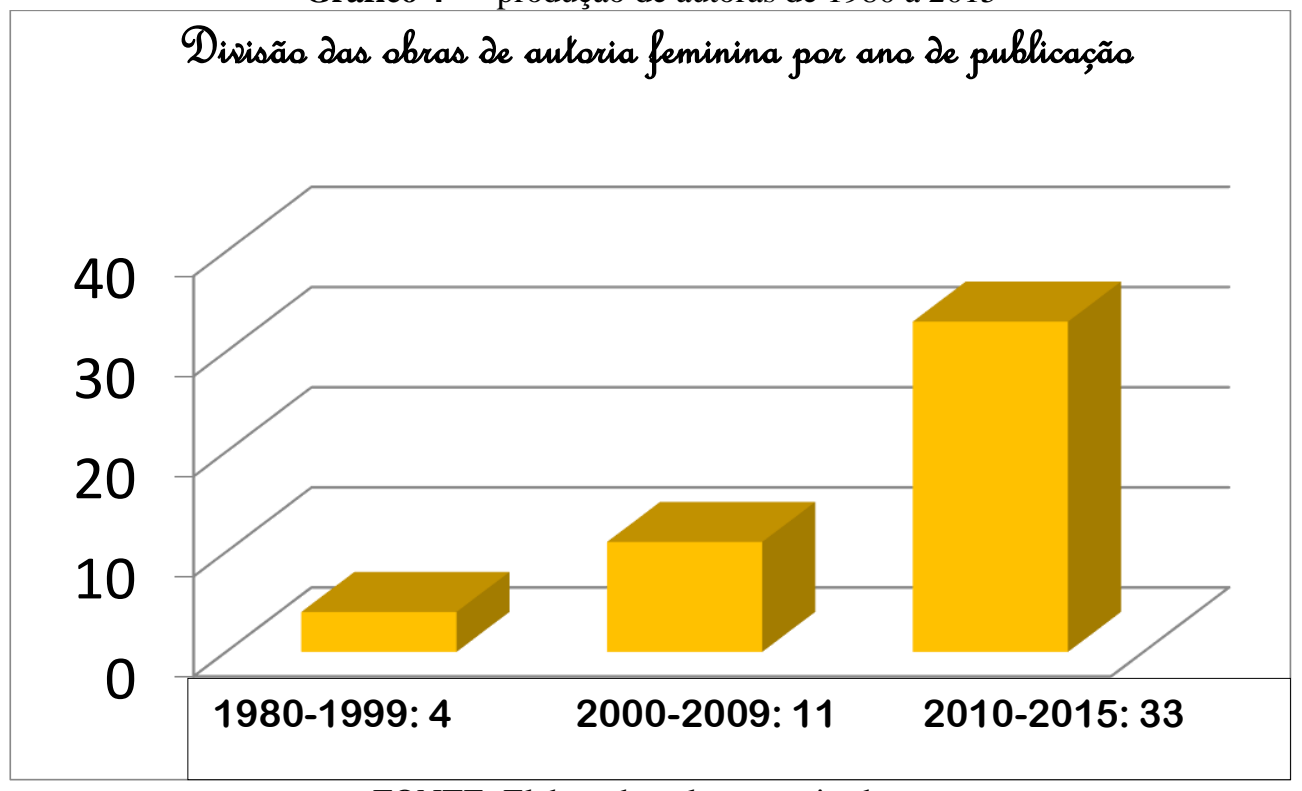

FONTE: Elaborado pelas pesquisadoras

Outro aspecto que julgamos fundamental quanto ao fato de se levar a obra literária para a sala de aula de crianças desde cedo é o protagonismo feminino, isso porque quando se apresenta autoras e autores em um mesmo patamar, tem-se mais chances de se ajudar na construção de seres humanos que respeitem a mulher enquanto capaz de realizar as mesmas atividades que o homem, dentre estas, a escrita literária. Embora quando se pense no papel feminino na sociedade, quase sempre se considere o seu lugar de educadora e cuidadora, é importante colocar em evidência a mulher neste lugar de quem escreve e publica é importante colocar em destaque, uma vez que, historicamente, o lugar de escrever/saber é dado ao homem. Ressalte-se ainda que há escritoras notadamente feministas a exemplo da antilhana Maryse Condé que também têm obras endereçadas ao público infantil e juvenil. 
Esse é também um de nossos intentos ao levar a literatura "dita francófona" para o ensino do francês para crianças; pois, afora o fato de ajudar a criança, levando a ela outro idioma, contribuindo para aberturas de novos horizontes linguísticos, os temas que essas obras abordam são fundamentais para dar às crianças e aos jovens um suporte necessário para a tolerância. Reflexões tais como as elaboradas por Chimamanda Ngozi Adichie (2017) contemplam a necessidade de ajudar crianças e jovens a não serem misóginos:

\begin{abstract}
Como nosso amigo Ikenga, sempre rápido em negar que qualquer coisa é causada pela misoginia, nunca interessado em escutar ou discutir, sempre dedicado a explicar como na verdade são as mulheres que são privilegiadas. Uma vez ele disse: “Ainda que a percepção geral seja de que meu pai manda em casa, na verdade, nos bastidores, é a minha mãe quem manda". Ikenga achava que estava refutando o sexismo, mas estava mesmo era reforçando meu argumento (p. 32-33).
\end{abstract}

É importante trazer debates desse tipo para a escola, (mesmo que esta não oferte cursos de francês para crianças) a fim de que em algum tempo tenhamos uma sociedade que contribua para a igualdade entre indivíduos, seja entre os gêneros, entre raças, classes sociais ou qualquer outra forma que instigue qualquer tipo de preconceitos latente em nossas sociedades. Além do que, é indispensável confrontar o jovem e a criança às situações como a destacada por Adichie na citação acima, uma vez que, em grande parte das vezes, as pessoas não percebem que têm um comportamento sexista.

Entendemos que ao ofertar outra língua e, junto a ela, outras culturas, estaremos avançando para além de uma política linguística perversa que prevê, no Brasil, um ensino básico ancorado em uma única língua estrangeira na escola que diz contribuir para "Identificar o lugar de si e do outro em um mundo plurilíngue e multicultural, refletindo, criticamente, sobre como a aprendizagem da língua inglesa contribui para a inserção dos sujeitos no mundo globalizado, inclusive no que concerne ao mundo do trabalho" (BNCC, 2018, p. 202, negritos nossos). O documento parece não atentar para o fato de que um mundo plurilíngue e multicultural não pode ser e não é acostado em uma única língua e, atrelada a ela, uma única cultura. Por essa razão, o nosso olhar que propõe caminhos para a leitura literária a partir de literaturas de língua francesa do continente africano é, por assim dizer, muito mais eficaz para inserir os sujeitos no mundo globalizado.

O nosso enfoque ainda dá conta de que quando se apresenta a literatura "francófona" desde cedo, o aprendiz terá mais chances de, realmente, ampliar seu conhecimento, exercitando o protagonismo social, como também propõe a BNCC (2018, p. 202, itálicos nossos) - tendo na língua inglesa o seu alvo - "como ferramenta de acesso ao conhecimento, de ampliação para 
a compreensão dos valores e interesses de outras culturas e para o exercício do protagonismo social". Entendemos que, apenas facultando outras línguas/literaturas/culturas aos aprendizes, em qualquer fase da vida, será possível, de fato, tocar a dimensão intercultural como propõe o mesmo documento nacional, estimulando a "Reflexão sobre aspectos relativos à interação entre culturas [...] de modo a favorecer o convívio, o respeito, a superação de conflitos e a valorização da diversidade entre os povos" (BNCC, 2018, p. 202). Compreendemos que nunca será possível realizar amplitude linguística e cultural dando-se o valor que tem a diversidade entre seres humanos de culturas distintas a partir de uma única língua, haja vista que, junto a ela, estão outros elementos fundamentais como a cultura daquele povo.

Embora o documento parametrizador do ensino básico brasileiro seja claro, é importante que, enquanto professores, vejamos além do que se quer mostrar, pois ensinar outras línguas é também mostrar outros mundos aos aprendizes. A partir da experiência com um idioma que parece não ser prioridade para o ensino brasileiro, como o francês, mas que traz consigo culturas de países presentes em todos os continentes e oceanos que cortam o planeta Terra, pode-se, de fato, ampliar valores e estimular trocas interculturais em espaços plurilíngues e pluriculturais.

\section{Algumas conclusões}

Este texto se propôs a discutir a importância da leitura literária na infância, no âmbito do ensino de uma língua estrangeira como a francesa. Ressaltamos que esse ensino desde cedo pode ser um potente suporte na formação humana em toda a sua complexidade. Apresentar às crianças e aos jovens obras literárias escritas em francês, por exemplo, pode ser um caminho para ampliação de horizontes. A leitura literária pode, de modo muito especial, instigar, provocar a curiosidade para o diferente, evitando-se que a criança conheça apenas um lado da história, conforme argumenta Adichie (2019) em O perigo de uma história única; por isso, compreendemos que ler obras africanas em francês é também ajudar a conhecer o outro lado das histórias.

Nosso intento com o trabalho que temos desenvolvido há alguns anos é, acima de tudo, estimular o gosto pela leitura, além de ajudar o aprendiz a descobrir mundos e confrontar-se com verdades estabelecidas ao longo da História e que parecem ser estáveis. É para ajudar o aprendiz e o professor a verem o outro e também a desenvolverem o gosto pela leitura, pois, o fato de ser em outra língua não deve ser um elemento limitador, uma vez que, enquanto linguagem, a literatura, por si só, já seria um obstáculo para a compreensão. Mas, não estamos nos referindo à tradução ou a algo parecido, fazemos referência às leituras, pois é preciso ler e ajudar na formação de leitores. Ler obras ficcionais, como nos ensina a própria Adichie (2017): 


\begin{abstract}
Ensine Chizalum a ler. Ensine-lhe o gosto pelos livros. A melhor maneira é pelo exemplo informal. Se ela vê você lendo, vai entender que a leitura tem valor. Se ela frequentasse a escola e simplesmente lesse livros, provavelmente se instruiria mais do que uma criança com educação convencional. Os livros vão ajudá-la a entender e questionar o mundo, vão ajudá-la a se expressar, vão ajudá-la em tudo o que ela quiser ser- chefs, cientistas, artistas, todo mundo se beneficia das habilidades que a leitura traz. Não falo dos livros escolares. Falo de livros que não têm nada que ver com a escola: autobiografias, romances, histórias (p. 34).
\end{abstract}

Não obstante a problemática que envolve ler uma obra literária em qualquer que seja o idioma, é necessário apresentar à criança os novos sons de uma língua que seja a dela, é necessário expor o adolescente a uma cultura que não seja a sua, a fim de que ele perceba quão amplo é o mundo no qual estamos. Trabalhar pela aprendizagem de uma língua em diálogo com a leitura literária é colocar o aprendiz diante de um universo maior, ampliando, assim, o seu mundo, levando-o construir os mais diversos questionamentos necessários para o crescimento individual.

Em tempos de concluir as nossas discussões, retomamos a fala de Chimamanda $\mathrm{N}$. Adichie ao afirmar: "Ensine Chizalum a questionar. A linguagem é o repositório dos nossos preconceitos, de nossas crenças, de nossos pressupostos. Mas, para lhe ensinar isso, você terá de questionar sua própria linguagem" (2017, p. 35). E, então, encerrando, reafirmamos entender que a própria noção subjacente no termo "francofonia", dada toda a problemática do seu entorno que ainda desperta, pode ser um espaço sine qua non para abrir novos mundos, ligando os estímulos da criança, conduzindo-a a ser um ser humano mais tolerante e aberto ao outro.

\title{
Referências
}

ADICHIE, Chimamanda Ngozi. O perigo de uma história única. Trad. Julia Romeu. São Paulo: Companhia das letras, 2019.

ADICHIE, Chimamanda Ngozi. Para educar crianças feministas: um manifesto. Trad. Denise Bottmann. São Paulo: Companhia das letras, 2017.

AIALA, Renata; MELLO, Renato de. Le texte littéraire en classe de français langue étrangère (FLE). Revista Letras Raras, Campina Grande, v. 4, n. 1, p. 9-19, 2015.

ARIÈS, Philippe. História Social da Criança e da Família. 2. ed. Trad. Dora Flaksman. Rio de Janeiro: LTC Editores, 2017.

ARRUDA, Larissa de Souza. O lugar do texto literário na formação do professor de francês: um estudo de dois currículos universitários brasileiros. 2016. 159f. Dissertação (mestrado) - Universidade Federal do Rio de Janeiro, Faculdade de Letras, Programa de Pósgraduação em Letras neolatinas, Rio de Janeiro, 2016. 
BRASIL. Base Nacional Comum Curricular: Educação Infantil, Ensino Fundamental e Ensino Médio. Brasília: MEC/Secretaria de Educação Básica, 2018.

CANDIDO, Antonio. O direito à literatura. In: . Vários escritos. 4. ed. Rio de Janeiro: Ouro sobre Azul, 2004. p. 169-191.

CARVALHO, Fernanda Antoniolo Hammes de. Neurociências e educação: uma articulação necessária na formação docente. Trab. Educ. Saúde, Rio de Janeiro, v. 8 n. 3, p. 537-550, nov. 2010/fev. 2011.

CHELEBOURG, Christian; MARCOIN, Francis. La littérature de Jeunesse. Paris: Amand Colin, 2007.

GAONAC'H, Daniel. L'apprentissage Précoce d'une Langue Étrangère : Le point de Vue de la Psycholinguistique. Paris: Hachette Livre, 2006.

LIRA, Mariana de Normando; PINHEIRO-MARIZ, Josilene. Literatura em aula de língua estrangeira para crianças: caminhos para aberturas de horizontes. Organon, Porto Alegre, v. 34, n. 66, p. 54, 2019.

MIRANDA, Déborah Alves; FLORÊNCIO Jéssica Rodrigues. Um olhar para o continente africano: considerações sobre a literatura infanto-juvenil na África de língua francesa. In: PINHEIRO-MARIZ, Josilene; OLIVEIRA, Maria Angélica de; QUEIROZ, Amarino. Algumas formas de ver as Áfricas. São Luís: EDUFMA, 2019. p. 198-212.

MORA, Francisco. Como funciona o cérebro. Porto Alegre: Artmed, 2004.

PEYTARD, J. et al. Littérature et classe de langue. Paris: Didier, 1982.

PINHEIRO-MARIZ, Josilene; LIRA, Mariana de Normando. On the use of children's literature in french as a foreign language classroom: teaching children in an exolingue context. Revista UNIABEU, Rio de Janeiro, v. 11, n. 28, p. 61-79, 2018.

PINHEIRO-MARIZ, Josilene; BITENCOURT, Manuella Barreto. Des remarques à propos de la littérature de jeunesse du Machrek. Revista Lumen et virtus, São Paulo, v. 9, n. 21, p. 4356, abr. 2018.

PINHEIRO-MARIZ, Josilene ; FLORÊNCIO, Jéssica Rodrigues. Introductory survey and study of children and juvenile francophone works. Humanising Language Teaching, v. 19, n. 3, p. 1-12, june. 2017.

PINHEIRO-MARIZ, Josilene. O livro didático no ensino de línguas estrangeiras como um espaço de práticas discursivas: confluências para relação entre língua e literatura. In:

CAVALCANTE, Luciana Rocha; CARNEIRO, Mônica Fontenelle; SANTOS, Naiara Sales Araújo (Orgs.). Ensino de línguas e práticas discursivas: múltiplos olhares. 1. ed. São Luiz: EDUFMA, 2016, p. 35-63.

POSLANIEC, Christian. Vous avez dit « littérature » ? Paris: Hachette Livre, 2002. 
REYES, Yolanda. A Casa Imaginária: Leitura e literatura na primeira infância. Trad. Marcia Frazão e Ronaldo Periassu. 1. ed. São Paulo: Global, 2010.

VANTHIER, Hélène. Techniques et Pratiques de Classe : L'enseignement aux Enfants en Classe de Langue. Paris: CLE International, 2009.

VYGOTSKY, Lev Semyonovich. Pensamiento y lenguaje. Trad. A. A. e P. R. Buenos Aires: Ediciones Fausto, 1995.

Recebido em: 18/05/2020

Aceito para publicação em: 24/08/2020

ANEXO 1 - Algumas obras que podem ser abordadas em aula de francês para crianças

Estas sinopses foram retiradas do corpus selecionado, tendo sido extraídas de sites especializados e dos livros físicos adquiridos em livrarias especializadas também. Todas as traduções foram feitas por: Josilene Pinheiro-Mariz, Jéssica Rodrigues Florêncio, Manuella Barreto Bitencourt e Ana Beatriz de Aquino Silva.

\begin{tabular}{|c|c|c|}
\hline \multicolumn{3}{|r|}{ ÁFRICA SUBSARIANA } \\
\hline \multicolumn{3}{|r|}{ História em quadrinhos } \\
\hline Obra & $\begin{array}{c}\text { Autores ou } \\
\text { autoras }\end{array}$ & Descrição da obra (sinopse) \\
\hline $\begin{array}{l}\text { Akissi, Tome 4: } \\
\text { Rentrée musclée }\end{array}$ & $\begin{array}{l}\text { Marguerite } \\
\text { Abouet } \\
\text { e Mathieu } \\
\text { Sapin }\end{array}$ & $\begin{array}{l}\text { Akissi, o destemido, tem medo da volta às aulas. Então ele fará de tudo para não ir à } \\
\text { escola, até mesmo se acidentar. Porque o que é melhor do que um pequeno acidente } \\
\text { para evitar o início das aulas? }\end{array}$ \\
\hline Aya de Yopougon & $\begin{array}{c}\text { Marguerite } \\
\text { Abouet }\end{array}$ & $\begin{array}{l}\text { Na década de 1970, a vida era doce na Costa do Marfim. Havia trabalho, os hospitais } \\
\text { eram equipados e as escolas eram obrigatórias. Eu tive a oportunidade de conhecer } \\
\text { este tempo despreocupado, onde os jovens não têm de escolher um dos lados muito } \\
\text { rapidamente, e só estavam preocupados com o cotidiano. E é justo o que quero contar } \\
\text { com Aya, uma África que permanece apesar de tudo, como se diz em nossos dias, "a } \\
\text { vida continua" (Marguerite Abouet). }\end{array}$ \\
\hline 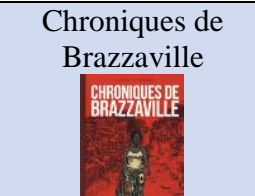 & $\begin{array}{l}\text { Lionnel } \\
\text { Boussi, } \\
\text { KHP, et al }\end{array}$ & $\begin{array}{l}\text { Uma HQ que abre e fecha com duas histórias do cartunista Koutawa Hamed Prisla, } \\
\text { conhecido por KHP. O primeiro conto tem duas páginas de agosto de } 1997 \text {, retorna } \\
\text { a um episódio ordinário da guerra civil que paralisou o país durante meses. O } \\
\text { cartunista, nascido em } 1979 \text {, tornou-se interessado nessas questões históricas. }\end{array}$ \\
\hline $\begin{array}{l}\text { Des clandestins à la } \\
\text { mer: Les } \\
\text { tribulations de } \\
\text { Yado }\end{array}$ & $\begin{array}{l}\text { Pie } \\
\text { Tshibanda }\end{array}$ & $\begin{array}{l}\text { Negro americano em busca de suas raízes, Yado chega ao Senegal, onde se encontrou } \\
\text { com o antigo amigo Masikini. Sendo este último convidado de ir à França, os dois } \\
\text { novos amigos decidem ir lá juntos. }\end{array}$ \\
\hline
\end{tabular}




\begin{tabular}{|c|c|c|}
\hline $\begin{array}{l}\text { Grand-père } \\
\text { raconte-nous le } \\
\text { Congo } \\
\text { Le congo } \\
\end{array}$ & $\begin{array}{l}\text { Mélanie } \\
\text { Yhomby- } \\
\text { Opango, } \\
\text { Thomas } \\
\text { Matali, } \\
\text { Grégory } \\
\text { Kounga }\end{array}$ & $\begin{array}{l}\text { A história começa no momento da luta pela independência, com a figura de André } \\
\text { Matsoua, mas também de outros intelectuais africanos que evocam sucessivamente } \\
\text { os seis presidentes congoleses e destaca momentos: políticos, econômicos, culturais } \\
\text { e desportivos, bem como as guerras civis do país. Estes momentos de "tristeza", } \\
\text { "vergonha" e "sofrimento" são considerados como características de aprendizagem. } \\
\text { Assim, o livro centra-se nos aspectos positivos destes } 50 \text { anos, evitando polêmicas e } \\
\text { salienta a necessidade de preservar a unidade do país, como uma família, as pessoas } \\
\text { "devem permanecer unidas apesar das diferenças." }\end{array}$ \\
\hline $\begin{array}{l}\text { Les aventures de } \\
\text { P'tit Filou }\end{array}$ & $\begin{array}{l}\text { Koffivi } \\
\text { Assem }\end{array}$ & $\begin{array}{l}\text { Port-au-Prince, P'tit Filou é uma criança do mercado de ferro. Ele furta para comer, } \\
\text { mas ele ama a sua vida de criança de rua. Após o grande terremoto que destruiu a } \\
\text { cidade, um jornalista lhe oferece comida contendo um sonífero. P'tit Filou acorda a } \\
\text { bordo de um navio com outras crianças, indo para os Estados Unidos para adoção. } \\
\text { Rebelde, P'tit Filou procura uma maneira de escapar. A decisão de uma das crianças } \\
\text { para lançar-se ao mar, para ir ao Haiti nadando, deixa clara a crueldade do jornalista } \\
\text { e seu negócio. }\end{array}$ \\
\hline $\begin{array}{l}\text { Les Aventu } \\
\text { Tigboli : Le } \\
\text { mensons }\end{array}$ & $\begin{array}{l}\text { Michel G. } \\
\text { Aïsse }\end{array}$ & $\begin{array}{l}\text { Tigboli é um jovem estudante que passa a vida a mentir para sobreviver. } \\
\text { Inevitavelmente, uma mentira leva a outra, maior ainda, e assim por diante. }\end{array}$ \\
\hline Les Enva & $\begin{array}{l}\text { Benjamin } \\
\text { Kouadio }\end{array}$ & $\begin{array}{l}\text { Abidjan, Costa do Marfim. Sika Saibon, contador da empresa Touvabien, } \\
\text { pacificamente vive com sua esposa e dois filhos. Até o dia em que a paz é perturbada } \\
\text { pela chegada de convidados indesejados: os invasores. De onde eles vieram? Quem } \\
\text { são eles? O que eles querem? Qual é a sua missão? Eles vão alcançar seus objetivos? } \\
\text { Este álbum convida o leitor para um universo impregnado de humor ao jeito africano. } \\
\text { (Ilustrações em preto e branco). }\end{array}$ \\
\hline $\begin{array}{l}\text { Les Diamants de } \\
\text { Kamituga } \\
\text { Difuring }\end{array}$ & $\begin{array}{l}\text { Séraphin } \\
\text { Kajibwami }\end{array}$ & $\begin{array}{l}\text { Asha, uma mãe é infectada pelo HIV, conta sua vida aos jovens. Ela conta como seu } \\
\text { marido Mayele, que por muito tempo estava desempregado, finalmente consegue ser } \\
\text { contratado pelas Minas Kamituga. Ao longo das páginas, observamos em Diamonds } \\
\text { Kamituga, uma história baseada em fatos reais, mergulha-nos na vida diária das } \\
\text { pessoas da República Democrática do Congo. Este testemunho é desolador repleto } \\
\text { de sinceridade e portador da mensagem fundamental da luta contra a AIDS. }\end{array}$ \\
\hline & Joëlle Esso & $\begin{array}{l}\text { Este livro apresenta seis histórias curtas que ocorrem na escola primária de Petit Joss, } \\
\text { na década de } 1970 \text {, em Douala, Camarões: duas meninas, boas alunas. Um eclipse } \\
\text { provoca medo em toda a classe. }\end{array}$ \\
\hline $\begin{array}{l}\text { Sur les berges du } \\
\text { fleuve Congo }\end{array}$ & $\begin{array}{l}\text { Alix Fuilu, } \\
\text { Willy Zekid } \\
\text { e Alain } \\
\text { Kojélé }\end{array}$ & $\begin{array}{l}\text { Esta é uma narrativa que aborda temas muito delicados na vivência das adolescentes } \\
\text { no Congo. Estupro, AIDS, ansiedade, estresse constituem-se no fio condutor da } \\
\text { história, quando após um estupro, o exame de Ma'Dembo revela soropositividade } \\
\text { para HIV. Assim, o estresse e a angústia, assim como outros sentimentos semelhantes } \\
\text { instalam-se na vida de Ma'Dembo, Massaka e Modi Michel. }\end{array}$ \\
\hline $\begin{array}{l}\text { Savane bien } \\
\text { savane bien }\end{array}$ & $\begin{array}{l}\text { Pierre } \\
\text { Genton }\end{array}$ & $\begin{array}{l}\text { Lamine, um menino da cidade, visita sua avó na aldeia durante os feriados. Ele } \\
\text { conheceu Keifa, um menino com uma doença que não é comum. De volta à cidade, } \\
\text { Lamine fica doente também. Ele foi imediatamente levado para o hospital, onde foi } \\
\text { diagnosticado com epilepsia. Com mais sorte do que Keifa que não recebeu nenhum } \\
\text { tratamento. Lamine vai tentar ajudar. }\end{array}$ \\
\hline $\begin{array}{l}\text { Thembi et Jetje, } \\
\text { tisseuses de l'arc- } \\
\text { en-ciel }\end{array}$ & $\begin{array}{l}\text { Christophe } \\
\text { Edimo }\end{array}$ & $\begin{array}{l}\text { Em dez capítulos ilustrados por nove artistas diferentes, contam a história de duas } \\
\text { famílias, uma Afrikaner, a outra Ndebele da África do Sul ao longo de vinte anos. A } \\
\text { história começa com a libertação de Nelson Mandela, que anuncia uma nação arco- } \\
\text { íris, desejada por Mandela e Desmond Tuto. }\end{array}$ \\
\hline \multicolumn{3}{|r|}{ Nouvelles } \\
\hline Obra & Autor & Descrição da obra (sinopse) \\
\hline
\end{tabular}




\begin{tabular}{|c|c|c|}
\hline $\begin{array}{l}\text { Le Rêve du } \\
\text { charpentier }\end{array}$ & Alain Taill & $\begin{array}{l}\text { Nove histórias compõem este livro, com ilustrações em preto e branco. Elas contam } \\
\text { histórias muito diferentes: um adolescente maltratado por seu pai por causa do sonho } \\
\text { de se tornar um famoso guitarrista e que encontra esperança e amor com uma } \\
\text { prostituta; um jovem mendigo em busca de um par de sapatos de verniz preto comete } \\
\text { um crime sangrento; um carpinteiro tem um sonho de liberdade e consegue se tornar } \\
\text { pregador antes de ser preso e executado; uma garota tenta fugir em vão para seu } \\
\text { destino como mulher e sacerdotisa do grande gênio da água; etc. }\end{array}$ \\
\hline $\begin{array}{l}\text { Mad l'Africain } \\
\text { man } \\
\text { Lajenily }\end{array}$ & $\begin{array}{l}\text { Vincent } \\
\text { Crouzet }\end{array}$ & $\begin{array}{l}\text { Mad Froggy é um motorista de um táxi coletivo e é o terror da polícia local, pois } \\
\text { dirige como um louco. Quando não está trabalhando no o táxi, Mad é vigia e } \\
\text { jardineiro de uma discreta mansão de uma estrela do cinema sul-africano que vive } \\
\text { em Hollywood. A narrativa ancora-se em } 2011 \text {, em um período de paz na África do } \\
\text { Sul, como um fim do Apartheid que era a base da segregação racial. }\end{array}$ \\
\hline $\begin{array}{l}\text { Un enfant comme } \\
\text { les autres }\end{array}$ & Pabé Mongo & $\begin{array}{l}\text { Papa Mongo é uma criança como qualquer outra. Tradicionalmente, ele passa as } \\
\text { férias escolares na aldeia. Ele, então, mergulha feliz no universo próximo da } \\
\text { natureza. }\end{array}$ \\
\hline \multicolumn{3}{|r|}{ Contos } \\
\hline Obra & Autor & Descrição da obra (sinopse) \\
\hline $\begin{array}{l}\text { Ayanda la petite } \\
\text { fille qui ne voulait } \\
\text { pas grandir }\end{array}$ & $\begin{array}{l}\text { Véronique } \\
\text { Tadjo }\end{array}$ & $\begin{array}{l}\text { Ayanda era uma menina feliz, sempre sorrindo. Um dia, uma terrível guerra eclodiu. } \\
\text { Uma guerra sem sentido. O pai dela, tão doce, tão gentil, foi forçado a ir lutar. Ele } \\
\text { nunca mais voltou. O coração de Ayanda foi quebrado. Sua tristeza se transformou } \\
\text { em raiva. Ela então decidiu parar de crescer. }\end{array}$ \\
\hline $\begin{array}{l}\text { Comment le désert } \\
\text { a disparu }\end{array}$ & $\begin{array}{l}\text { Isabelle } \\
\text { Hoarau }\end{array}$ & $\begin{array}{l}\text { Esse livro conta a história de um sábio que trabalha contra a desertificação através } \\
\text { do plantio de árvores. Este livro foi inspirado por um projeto de plantação de árvores } \\
\text { no Senegal, foram plantadas mais de } 10.000 \text { árvores para ajudar o povo do Senegal } \\
\text { a se reconectar com suas tradições, afim de fortalecer as ancestralidades pela } \\
\text { medicina tradicional/popular, combatendo, assim, a desertificação que nesse país } \\
\text { cresce a cada ano. }\end{array}$ \\
\hline $\begin{array}{l}\text { Contes merveilleux } \\
\text { et contes drôles de } \\
\text { la savane }\end{array}$ & $\begin{array}{l}\text { Virginie } \\
\text { Mouanda } \\
\text { Kibinde }\end{array}$ & $\begin{array}{l}\text { Dez textos que compõem esta primeira coleção de Virginia Mouanda Kibinde. Estes } \\
\text { contos são, em sua maioria, de sua aldeia. Restauram o tom e o ritmo de músicas ou } \\
\text { formulações orais esmaltadas (em uma língua cujo nome não é especificado) e às } \\
\text { vezes também uma crueza nua e crua ao lado de um tom engraçado. }\end{array}$ \\
\hline $\begin{array}{l}\text { Fatacumba et } \\
\text { autres Contes de } \\
\text { Mauritanie }\end{array}$ & $\begin{array}{l}\text { Mamadou } \\
\quad \text { Sall }\end{array}$ & Oito histórias curtas em um estilo animado, divertido de ler em voz alta. \\
\hline $\begin{array}{c}\text { L'Arbre au secret } \\
\text { L'arbre au secret } \\
\text { Cys }\end{array}$ & John Kilaka & $\begin{array}{l}\text { Um dia, a seca se instala na terra dos animais, logo seguida pela fome. Uma grande } \\
\text { árvore continua a dar frutos maravilhosos. Mas os animais não colhem os frutos, pois } \\
\text { permanecem ligados à árvore. Um pequeno coelho teve a ideia de pedir um conselho } \\
\text { a uma tartaruga sábia. }\end{array}$ \\
\hline $\begin{array}{c}\text { La Fête de Ya } \\
\text { foufou: Congo- } \\
\text { Brazzaville }\end{array}$ & $\begin{array}{l}\text { Patrick S. } \\
\text { Boutsindi }\end{array}$ & $\begin{array}{l}\text { Entre os animais da floresta, Ya foufu, roedor, vive sozinho. Um dia, ele decide fazer } \\
\text { uma festa e convida todos os seus amigos: o leão, o crocodilo, o javali, o elefante, o } \\
\text { macaco e a lebre e pediu a todos para trazerem um item de alimentos. Qual não é a } \\
\text { grande surpresa que acontece nessa festa? }\end{array}$ \\
\hline $\begin{array}{l}\text { La pintade et le } \\
\text { serpent }\end{array}$ & $\begin{array}{l}\text { Perpétue } \\
\text { Hounnou } \\
\text { Affomasse }\end{array}$ & $\begin{array}{l}\text { Para comer, a pintada confia seus ovos à serpente. Em seu retorno, ela teve uma má } \\
\text { surpresa. }\end{array}$ \\
\hline
\end{tabular}




\begin{tabular}{|c|c|c|}
\hline 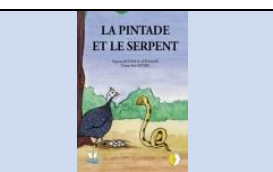 & & \\
\hline $\begin{array}{l}\text { Le Baluchon de la } \\
\text { création du monde } \\
\text { et autres contes } \\
\text { yorouba }\end{array}$ & $\begin{array}{l}\text { Pauline } \\
\text { Penot, } \\
\text { Sabine } \\
\text { Panet }\end{array}$ & $\begin{array}{l}\text { Nos porões dos navios negreiros, escravos arrancados da África transportados para } \\
\text { as tradições do Novo Mundo e de seus deuses. Na Bahia, no nordeste do Brasil, o } \\
\text { Yoruba do Golfo da Guiné perpetua seus cultos e implanta suas divindades, os } \\
\text { Orixás. Estes combinam contos de raízes do Oeste Africano, uma influência } \\
\text { brasileira, e a marca da imaginação dos autores. }\end{array}$ \\
\hline $\begin{array}{l}\text { L'Étoile, l'Oiseau } \\
\text { et le Poisson }\end{array}$ & $\begin{array}{l}\text { Fousséni } \\
\text { Mamah }\end{array}$ & $\begin{array}{l}\text { Um peixe, uma estrela e uma ave selvagem são escravos de senhora Galinha. } \\
\text { Cansados da ingratidão dessa personagem rica e caprichosa, eles decidem fugir e } \\
\text { encontrar a liberdade de seu universo inicial. }\end{array}$ \\
\hline $\begin{array}{l}\text { La Formule } \\
\text { magique; Auteur : } \\
\text { Ibrahima Ndiaye } \\
\text { La formule } \\
\text { magique } \\
\\
\end{array}$ & $\begin{array}{l}\text { Ibrahima } \\
\text { Ndiaye }\end{array}$ & $\begin{array}{l}\text { A fórmula mágica fala de animais da savana, com fome por causa da seca, que } \\
\text { decidem ir, em uma caravana em busca de alimento. Mas, para colher o fruto da } \\
\text { árvore que eventualmente encontram, eles precisam de uma fórmula mágica! }\end{array}$ \\
\hline $\begin{array}{l}\text { Le Bel Oiseau et la } \\
\text { Pluie } \\
\text { Pand }\end{array}$ & $\begin{array}{l}\text { Véronique } \\
\text { Tadjo }\end{array}$ & $\begin{array}{l}\text { Esta é a estação seca. As árvores já não têm uma única folha. Homens e animais têm } \\
\text { muita sede. Eles vão em busca de água. }\end{array}$ \\
\hline 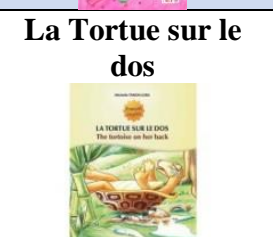 & $\begin{array}{l}\text { Michelle } \\
\text { Tanon-Lora }\end{array}$ & $\begin{array}{l}\text { A tartaruga é muito lenta quando caminha, por esta razão, é muito triste. Um dia, ela } \\
\text { embarca em uma aventura. Desde então, ela está feliz por ser capaz de seguir em } \\
\text { frente, mesmo que não seja tão rápido quanto outros animais. }\end{array}$ \\
\hline $\begin{array}{l}\text { Le Rêve du singe: } \\
\text { Contes du Bénin }\end{array}$ & $\begin{array}{c}\text { Armel } \\
\text { Nonfodji }\end{array}$ & $\begin{array}{l}\text { Este livro é composto de seis histórias. Seis contos que querem mais ou menos } \\
\text { explicar a origem das coisas. }\end{array}$ \\
\hline Mon frère, l'hyène & $\begin{array}{l}\text { Omar } \\
\text { Youssouf } \\
\text { Ali }\end{array}$ & $\begin{array}{l}\text { A bravura, a beleza e a bondade de Ahmed, órfão jovem e bonito caçador, são de } \\
\text { admiração de todos. Sobretudo quando faz as hienas caírem em armadilhas, } \\
\text { protegendo assim, os rebanhos da cidade. Entretanto, curiosamente, ao vê-lo, a hiena } \\
\text { não foge, como se perdesse as forças e, então o jovem guerreiro não a mata. Essa } \\
\text { atitude provoca interesse das pessoas. Com esse comportamento curioso, o jovem } \\
\text { começa então a contar a sua história dentro da história. }\end{array}$ \\
\hline $\begin{array}{l}\text { Toutes petites } \\
\text { histoires du } \\
\text { Kilimandjaro }\end{array}$ & Patrick Fort & $\begin{array}{l}\text { Este livro é composto por dez histórias de vida que se prestam à leitura oral, } \\
\text { emanando ternura e humor. Os textos fornecem uma grande porta para a imaginação. }\end{array}$ \\
\hline Un voleur malin & $\begin{array}{l}\text { E. Domche } \\
\text { Teko }\end{array}$ & $\begin{array}{l}\text { Um ladrão de cabra, apanhado em flagrante pelo proprietário, afirma ter ido até lá } \\
\text { para contar os dentes de animais para fins científicos. Assim, ele consegue escapar e } \\
\text { fugir. Uma história engraçada, de forma precisa e belamente ilustrada pelo cartunista } \\
\text { de talento reconhecido, cujas cenas cômicas certamente farão o público jovem rir. }\end{array}$ \\
\hline & & Romances \\
\hline Obra & Autor & Descrição da obra (sinopse) \\
\hline
\end{tabular}




\begin{tabular}{|c|c|c|}
\hline $\begin{array}{l}\text { Le Destin } \\
\text { d'Aïssata }\end{array}$ & $\begin{array}{l}\text { Jessica } \\
\text { Reuss- } \\
\text { Nliba, } \\
\text { Didier Reu }\end{array}$ & $\begin{array}{l}\text { A mais nova da família, Aissata é também aquela que pode esgueirar-se mais } \\
\text { profundamente na mina de diamantes e trazer as pedras mais bonitas que seu pai } \\
\text { vende todas as semanas em Korhogo na Costa do Marfim. Seu maior prazer era } \\
\text { acompanhá-lo nessas vendas para que ela pudesse ver a luz do dia. Foi nessa época } \\
\text { que ela descobriu a escola de canto cuja professora abriu as portas, dando a } \\
\text { oportunidade. Sua vontade, seu desejo de ter sucesso, seu trabalho e o apoio de sua } \\
\text { mãe e irmãs lhe permitiram realizar o seu sonho. }\end{array}$ \\
\hline $\begin{array}{l}\text { Le Royaume du } \\
\text { cœur }\end{array}$ & $\begin{array}{l}\text { Josette } \\
\text { Desclercs } \\
\text { Abondio }\end{array}$ & $\begin{array}{l}\text { A vida de Sharon, uma jovem americana de treze anos, mimada e que vive na Costa } \\
\text { do Marfim desde muito tempo. Sua vida cai por terra quando seus pais se separaram. } \\
\text { Ela fica com seu pai em Abidjan, enquanto sua mãe foi mandada de volta para os } \\
\text { Estados Unidos. }\end{array}$ \\
\hline $\begin{array}{l}\text { Myriam et le Prince } \\
\text { d'Angleterre }\end{array}$ & $\begin{array}{l}\text { Zeïna } \\
\text { Haïdara }\end{array}$ & $\begin{array}{l}\text { Myriam, princesa "mandinka", é "uma guerreira formidável e excepcional caçadora" } \\
\text { para desespero de sua mãe, que quer vê-la abandonar essas atividades masculinas } \\
\text { para se casar. Mas a vida da menina vai dar uma virada dramática com a chegada de } \\
\text { homens "sem pele": seu pai é morto e sua irmã sequestrada, a menina persegue esses } \\
\text { brancos que vieram capturar os seus. }\end{array}$ \\
\hline $\begin{array}{l}\text { Une guérison qui } \\
\text { vient de loin }\end{array}$ & Zèce O’Bali & $\begin{array}{l}\text { Julia sofre de miastenia grave e não deve se cansar. Ela então pede ajuda à fada dos } \\
\text { oceanos. No Semontrijkal, África Subsaariana (lugar imaginário que pode ser } \\
\text { assumido como sendo a costa dos Camarões, região do autor do livro), Dipita Moudi, } \\
\text { pescador, encontra a carta de Julia dentro do ventre de um peixe. A narrativa é um } \\
\text { hino ao humanismo, à diversidade e ao respeito às crenças, tradições, costumes e } \\
\text { diversos meios de expressão da espécie humana. }\end{array}$ \\
\hline
\end{tabular}

\begin{tabular}{|c|c|c|}
\hline \multicolumn{3}{|r|}{ MAGREBE E MACHRECK } \\
\hline \multicolumn{3}{|r|}{ Contos } \\
\hline Obra & Autor & Descrição da obra (sinopse) \\
\hline $\begin{array}{l}\text { Chtim Chlim et la } \\
\text { fille du Sultan }\end{array}$ & $\begin{array}{l}\text { Nezha } \\
\text { Lakhal } \\
\text { Chevé }\end{array}$ & $\begin{array}{l}\text { Para esta criação, o autor foi inspirado pelos contos Mil e Uma Noites e contos e } \\
\text { histórias coreanas. Este livro comporta um conto musical que a criança poderá tanto } \\
\text { ler como ouvir a história. }\end{array}$ \\
\hline $\begin{array}{l}30 \text { contes du } \\
\text { Maghreb }\end{array}$ & Jean Muzi & $\begin{array}{l}\text { Estes trinta contos do Magrebe não respeitam fronteiras: eles têm viajado tanto que } \\
\text { às vezes é difícil dizer se eles são marroquinos, argelinos ou tunisianos. } \\
\text { Os homens estão ao lado de animais e criaturas míticas. Ele mostra os fracos e } \\
\text { oprimidos que triunfam graças às suas astúcias. Trinta contos para descobrir a alma } \\
\text { do Magrebe. }\end{array}$ \\
\hline $\begin{array}{l}\text { Le Voyage de Pois } \\
\text { Chiche } \\
\text { vol } \\
\text { aticie } \\
\text { and }\end{array}$ & $\begin{array}{l}\text { Nezha } \\
\text { Lakhal } \\
\text { Chevé }\end{array}$ & $\begin{array}{l}\text { Esta é a história de um garotinho, do tamanho de um grão de bico, seus pais o chamam } \\
\text { de H'mimsa, (h'moss é o nome de grão de bico em árabe). Sua mãe faz-lhe } \\
\text { constantemente recomendações e prefere mantê-lo na sua casa. } \\
\text { Mas, um dia, ele conseguiu permissão para sair e brincar. Assim H'mimsa é } \\
\text { encontrado no campo, onde uma galinha o pega com o seu bico. Como será que ele, } \\
\text { H'mimsa, vai sair desta situação? }\end{array}$ \\
\hline $\begin{array}{c}\text { Le Mariage de } \\
\text { Mademoiselle } \\
\text { Khanfoussa }\end{array}$ & $\begin{array}{l}\text { Nezha } \\
\text { Lakhal- } \\
\text { Chevé }\end{array}$ & $\begin{array}{l}\text { Tanto as ilustrações quanto as histórias desse livro são engraçadas e representantes da } \\
\text { cultura marroquina }\end{array}$ \\
\hline $\begin{array}{l}\text { Les Légendes de } \\
\text { Casablanca }\end{array}$ & $\begin{array}{l}\text { Mostapha } \\
\text { Oghnia }\end{array}$ & $\begin{array}{l}\text { A cidade de Casablanca é pontilhada com pequenos santuários ou lugares cujos } \\
\text { nomes referem-se a uma lenda ou a um fato histórico. Cinco dessas histórias são } \\
\text { contadas neste livro. }\end{array}$ \\
\hline
\end{tabular}






Fonte: Elaborado pelas pesquisadoras 